Research Article

\title{
e-Learning versus e-Teaching: Seeing the Pedagogic Wood for the Technological Trees
}

\author{
Joanne L. Badge, Alan J. Cann, Jon Scott \\ School of Biological Sciences, University of Leicester, University Road, \\ Leicester, LE1 7RH, UK
}

Date received: 09/03/2005

Date accepted: 11/05/2005

\begin{abstract}
Most Virtual Learning Environments are designed to be simple to use by staff and students alike. We report a case study where this feature has led academic staff to reject formal centralised training and teach themselves how to use the system. What has resulted is widespread use of the system but with poor pedagogic development, leading primarily to an electronic document repository rather than an online learning tool which makes full use of the potential of the full suite of available tools. We describe what steps can be taken to avoid or remedy this problem.
\end{abstract}

Keywords: e-Learning, Virtual Learning Environment, Blackboard, staff development

\section{Introduction}

Virtual Learning Environments (VLEs) are now in widespread use in British Universities (Browne and Jenkins, 2003, Ward et al, 2001). The University of Leicester first deployed the Blackboard Virtual Learning Environment in May 2002. The School of Biological Sciences was an early adopter of the VLE and was the first to deploy an undergraduate module using online assessment. VLE usage is voluntary and at the discretion of the module convenor or Degree Teaching Team. In order to facilitate adoption of the VLE across the School of Biological Sciences, we conducted an audit of all module convenors by means of face-to-face interviews to complete a standardised questionnaire.

\section{Method}

The School offers 10 undergraduate degree streams, comprising 85 individual modules that are delivered by 62 convenors (assisted by other academic staff). Of the 62 convenors involved in teaching undergraduate modules, 47 were contacted to take part in the audit (some staff were not contacted as they were retiring, leaving the University or were involved in teaching a module that was soon to be terminated). They were approached first through departmental teaching team meetings and then on an individual basis. Initial consultation established their previous experience of Blackboard. The convenors were classed as established 'Blackboard users' if they had created a Blackboard site for a module that they convened by uploading teaching material to the system. Convenors were classed as 'Blackboard non-users' if they had either only used Blackboard to view material that was already online, or had never accessed the system at all. 
Two questionnaires were devised, Questionnaire 1 for those classed as Blackboard users and Questionnaire 2 for those classed as Blackboard nonusers (See Appendix A for a full list of questions). There were five common questions, referring to background information that was independent of Blackboard usage. These included hardware and software use, training attended, knowledge of SENDA requirements (Special Education Needs and Disability Act, 2001), future plans for using Blackboard and any sources of teaching on external websites. Open questions were used to try to encourage discussion of the issues raised and look for common themes.

For the Blackboard users, we recorded what features of the VLE they had employed in their courses, and whether they had used any form of summative or formative online assessment. We also asked what their motivation for using the VLE was and what factors prevented them from making greater use of the system. For non-users, we sought to determine the barriers hindering their use of the VLE.

\section{Results}

The response rate was $87 \%$. Face-to-face interviews were conducted with 41 staff, covering 66 modules. Sixty two percent of convenors surveyed used Blackboard. All of these users employed the software to make teaching documents available to students, and $85 \%$ used the inbuilt Announcements and Staff Information areas.

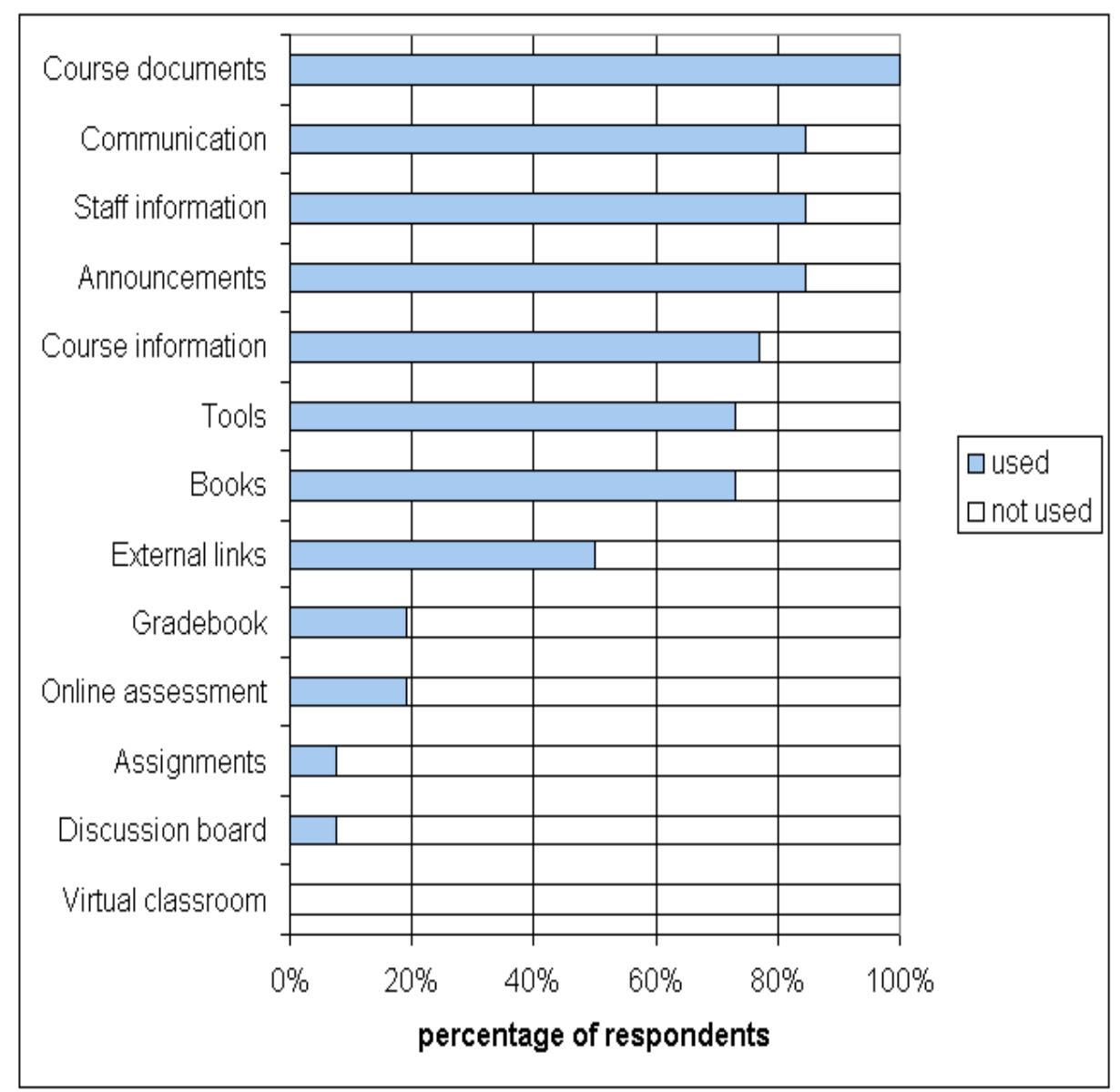

Figure 1 Facilities of Blackboard used by staff surveyed 
In contrast, only $19 \%$ of users attempted any sort of online assessment, and even fewer used the more sophisticated communications tools provided (Discussion Boards, 8\%; Virtual Classroom, 0\%). The majority of staff were using Blackboard as an alternative (or as a supplement) to providing printed handout material at the lecture. Only three modules used Blackboard tests for summative assessment. A small number required students to submit work electronically for marking (for example, essays written using MSWord), although even this was sometimes in addition to the same work being submitted as a hard copy (Figure 1).

General comments about why staff used Blackboard were collated (Figure 2, full answers listed in Appendix B). The most commonly cited reason (30\%) was that it led to student pull for information (i.e. searching out information for themselves) and provided an easy method to distribute lecture handouts. Peer pressure from colleagues (27\%) was the next most cited reason for starting to use Blackboard (Figure 2).
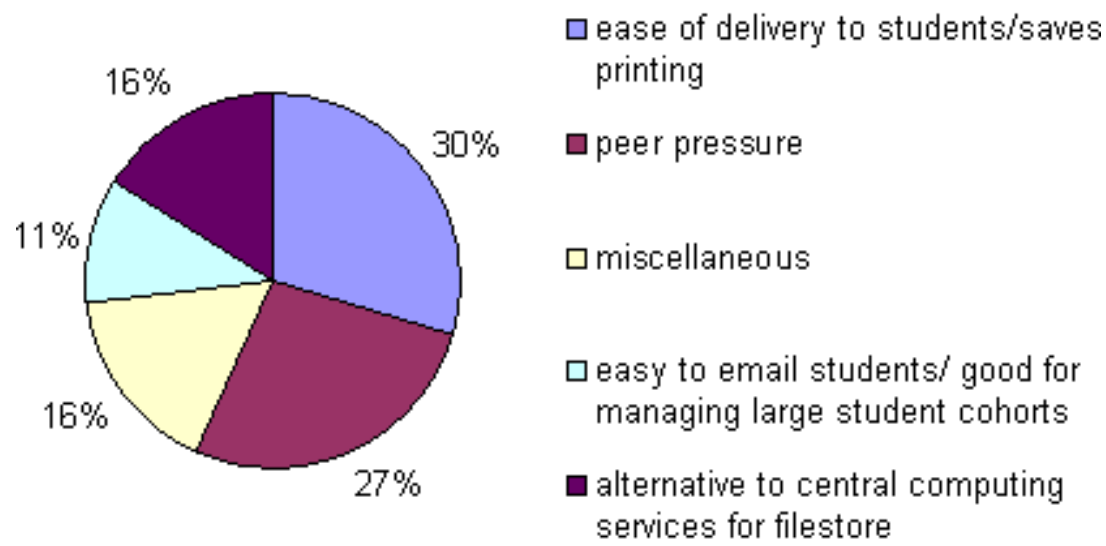
managing large student cohorts

alternative to central computing services for filestore

Figure 2 Reasons given by those classed as Blackboard users for why they first began to use the VLE

Over a third of staff admitted that lack of time was the biggest barrier to expanding their use of the system, and a fifth stated that they felt they did not have the knowledge required to go further (Figure 3). Interestingly, these were the same reasons given by non-users of Blackboard to explain why they did not use the system (Figure 4). Other reasons given as barriers to using Blackboard included reluctance to change from extensive existing web-based systems, concerns over copyright issues and pedagogical arguments against a culture of 'spoon feeding' information to students. 


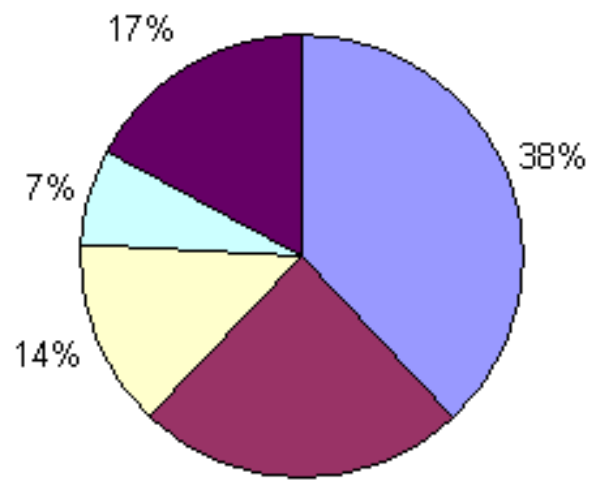

$24 \%$ 口lack of time

口lack of knowledge

$\square$ no improvement thought necessary

口technical problems

other

Figure 3 Reasons given by Blackboard users as to what factors prevent them from making greater use of the VLE

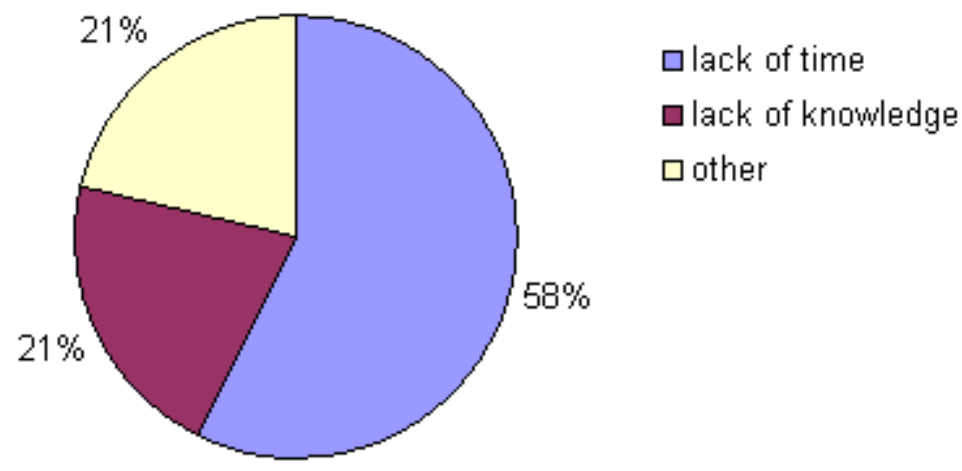

Figure 4 Barriers for Non-users to begin to use Blackboard

However, in spite of a comprehensive program of staff development and training in the use of the VLE, only $10 \%$ of staff in the School of Biological Sciences had received any centralised formal training in Blackboard, with the rest being entirely self-taught. There was widespread lack of knowledge of the SENDA legislation and how it applied to teaching material on Blackboard.

\section{Discussion}

Overall, there is relatively widespread adoption of the VLE throughout the School, and this is growing (shown by an increase in the proportion of modules now on Blackboard from 56 to $65 \%$ over the last semester).

The findings of this audit indicate that while many staff have used Blackboard to some extent, a large majority fail to make use of the potential pedagogical advantages offered by the full functionality of the software. A small percentage of staff had attended formal centralised staff development sessions, the majority of those classed as Blackboard users being self-taught. These results indicate that when academic staff begin to use a VLE in a selftaught environment, they do not consider how it can be used to improve the 
educational value of their teaching. Instead, it is seen as a quick way to deliver learning materials that would otherwise have been delivered by alternative means, e.g. printed handouts. In particular, time constraints and the naïve expectations that learning technology is either a bottomless pit or a quick technological fix for pedagogical problems result in the use of sophisticated C\&IT systems as mere filing systems - the lowest educational denominator.

The use of commercial VLE products far outweighs in-house or open source software (Browne and Jenkins, 2003). User-friendly interfaces for staff and students are therefore becoming more homogeneous and easier to navigate. Not surprisingly, recent evidence has shown 'simply putting notes on the web' does not improve student learning (Evans et al, 2004). However, Evans et al (2004) showed that material that is presented with sound pedagogical underpinning and which is easily navigable, appears to enhance student learning. Such findings are not always transmitted to the teaching community by centralised, non discipline-specific training, or other methods of institutional staff development. An easily accessible interface has the disadvantage of not guiding the contributor to consider the pedagogical development of the material they are adding to a VLE. In particular, there is evidence that little consideration is given by hard-pressed academic staff of how best to adapt the format of previous teaching materials and assessments for delivery via the VLE. A system of staff development needs to be found to allow staff to distinguish the pedagogic wood from the technological trees (e-Trees?).

Models for the establishment of VLEs and e-learning in university education suggest that it is a process which occurs in stages (Jevons and Northcott, 1994) along a continuum (Figure 5).

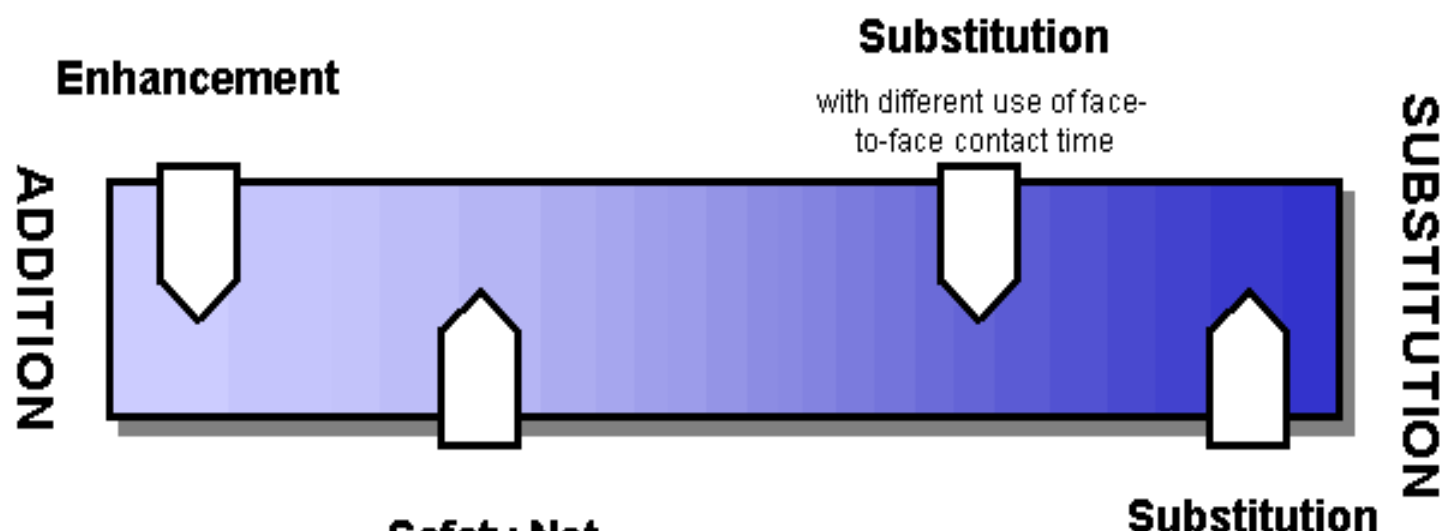

Safety Net

for face-to-face contact

Figure 5 Modes of adoption of e-learning (after Jevons and Northcott, 1994).

If this is so, our survey shows that there is little training required to reach the first stage of enhancement - transfer of existing teaching materials to a VLE. However, it is not clear how progression towards substitution should be 
encouraged or supported. With a reluctance to attend formalised training sessions to start using a new system such as a VLE, it is unlikely that academic staff will be encouraged to attend similar sessions for pedagogic considerations of e-learning to improve their online teaching. Peer pressure can present a barrier to attending training but can also be harnessed to promote best practice through well-respected pioneers in e-learning. Localised discipline-orientated training with subject specific examples can be made attractive and non-threatening to staff, especially where a team approach is taken to teaching.

How staff development handles this progression will be key to the development of e-learning in our Universities (Orsmond and Stiles, 2002). It is acknowledged that the experience of being a student in an online course increases the awareness of online tutors to the needs of their students (Salmon, 2002). One example of an online course about computer-aided assessment demonstrated that this approach is popular with academics and encouraged a sound approach to online assessment (Walker et al, 2004). Models for situated learning (learning embedded in the social and physical context within which it is used) have been shown to be popular and effective modes for change within universities (Taylor, 2003). Emphasis on the provision of exemplars of effective online teaching, faculty-based and discipline-based support, and a range of diverse options for staff learning (O'Reilly et al, 2000) will lead us forward from 'simply putting notes on the web' to providing an enhanced learning experience for our students, and to appreciate the difference between the simple, document repository-push response to VLEs which results in "e-Teaching", and the interactive, reflective, student-pull of well thought out e-Learning.

\section{Acknowledgements:}

We are grateful to the University of Leicester Fund for Faculty Teaching Initiatives for supporting the work described in this report.

Corresponding author: Dr Joanne Badge, School of Biological Sciences, University of Leicester, University Road, Leicester, LE1 7RH, UK.

Tel: 01162522909 Email: jlb34@le.ac.uk 


\section{References}

Browne, T. and Jenkins, M. (2003) VLE Surveys - a longitudinal perspective between March 2001 and March 2003 for Higher Education in the United Kingdom, UCISA. http://www.ucisa.ac.uk/groups/tlig/vle/vle2003.doc (accessed 9 March 2005)

Evans, C., Gibbons, N. J., Shah, K. and Griffin, D. K. (2004) Virtual learning in the biological sciences: pitfalls of simply "putting notes on the web" Computers \& Education, 43, 49-61

Jevons, F. and Northcott, P. (1994) Costs and Quality in Resource-Based Learning On and Off-Campus, National Board of Employment, Education and Training Commissioned Report No. 33. Canberra, Australia: Australian Government Publishing Service

O'Reilly, M., Ellis, A. and Newton, D. (2000) The Role of University Web Pages in Staff Development: Supporting Teaching and Learning Online, In AUsWeb2K, Sixth Australian World Wide Web Conference Cairns, Australia. Available online at http://ausweb.scu.edu.au/aw2k/papers/o reilly/paper.html (accessed 2 May 2005)

Orsmond, P. and Stiles, M. (2002) University Teaching: A challenge to Staff Development Innovations in Education and Teaching International, 39, 253255

Salmon, G. (2002) E-tivities: the key to active online learning. London, UK: Kogan Page

Special Educational Needs and Disability Act 2001. Available at http://www.hmso.gov.uk/acts/acts2001/20010010.htm (accessed 9 May 2005)

Taylor, J. A. (2003) Managing staff development for online education: a situated learning model. Journal of Higher Education Policy and Management, 25, 75-87

Walker, D., Adamson, M. and Parsons, R. (2004) Staff Education - Learning About Online Assessment, Online, In 8th International Computer Assisted Assessment Conference, (Ed, Ashby, M. W.) pp. 437-444 Loughborough, England. Available online at http://s-d.Iboro.ac.uk/caanew/pastConferences/2004/proceedings/Walker_Parsons.pdf (accessed 2 May 2005)

Ward, J. P. T., Gordon, J., Field, M. J. and Lehmann, H. P. (2001) Communication and information technology in medical education. The Lancet, 357, 792-796 


\section{Appendix A}

\section{Questionnaire 1 (for 'Blackboard users')}

- Software used (mac/windows / office/ adobe/ image processing/ web editing/ compression/)

- Do you have any teaching material on the web outside Blackboard?

- What percentage of your teaching is carried out on Blackboard?

- Facilities used on Blackboard

- Why do you use Blackboard?

- What prevents you from using Blackboard to a greater degree?

- Have you ever attended a training course on Blackboard? Or web development software?

- Are you aware of SENDA and its implications for Blackboard?

- Any modules to be added to Blackboard this 04/05 or 05/06?

- And forward plans for teaching on Blackboard

\section{Questionnaire 2 ('Blackboard non-users')}

- Software used mac /windows / office/ adobe/ image processing/ web editing/ compression/

- Do you have any teaching material on the web outside Blackboard?

- What percentage of your teaching is carried out on Blackboard?

- Why do you not use Blackboard?

- What prevents you from using Blackboard?

- Have you ever attended a training course on Blackboard? Or web development software?

- Are you aware of SENDA and its implications for Blackboard?

- Any modules to be added to Blackboard this 04/05 or 05/06?

- And forward plans for teaching on Blackboard 


\section{Appendix B}

\section{Questionnaire 1 (for 'Blackboard users') - open comments from interviewees}

\section{Why do you use Blackboard (Bb)?}

ease of delivery to students/saves printing -11

- ease of access of information for students, often slides present better on screen than as small handout, wanted more communication back from students (not received!)

- easier to put information online than print out, puts the onus on the student

- easy delivery of information, like having electronic copies of work time and date stamped

- much easier to upload information to $\mathrm{Bb}$ than to the web, email by groups is excellent, announcements is useful for first years

- obliged to use by position as example to others, does find it convenient to put images from lectures that do not reproduce well in printed material

- tool for delivery of material which is better in electronic format than printed URLs, graphics, programming

- uses less paper and student led to get information

- peer pressure, students like it, sensible way to organise information

- put the responsibility onto students, no handouts to print out

- saves a lot of printing

- save time and effort, popular with students, man management for large numbers students

\section{Peer pressure - 10}

- peer pressure, students like it, sensible way to organise information

- felt needed to and was encouraged to try after $\mathrm{Bb}$ demonstration given during interview

- heard about it, did initial training and started using

- obliged to use by position as example to others

- used after introduction session, peer pressure

- peer pressure from staff meeting, have found it useful

- peer pressure, hides non copyrighted information in password protected environment

- obliged to use by position as example to others, does find it convenient to put images from lectures that do not reproduce well in printed material

- because it was there and felt should use it but don't feel it has added to the quality of teaching

- was told to use it, easier than putting information on the web, convenient to do it piecemeal at your own pace

\section{Other -6}

- access for students on and off campus, gives a good impression

- tried version 5 and had problems without any training

- new lecturer, just taken over course to convene

- no specific reason

- to transfer existing information from web

- wanted a fully integrated course on a VLE 
alternative to central file store- 6

- as a file store and for the email distribution list

- used as a central file store, easy to contact students by email as a single group

- was putting material on central file store, $\mathrm{Bb}$ was more co-ordinated way of organising the information, and did not require a large cfs quota for storage

\section{What prevents you from using $\mathrm{Bb}$ to a greater degree?}

lack of time - 11

- lack of time (6 responses)

- lack of time and expertise (2 responses)

- lack of time and knowledge about how to set up assessments

- lack of time - investment and front loading, not appropriate for some teaching \& practicals

- put off by past difficulties, lack of time

lack of knowledge - 7

- lack of time and expertise (2 responses)

- lack of time and knowledge about how to set up assessments

- lack of knowledge

- lack of training

- no opportunity yet to use it, no training

- no time to learn new features

other - 5

- few features that would not use - cartridges (too prescribed), calendar

- would use it more for tutorials if students were motivated to participate in online discussions, if not assessed, don't participate

- not having absolute control within the course (co-convenor)

- feel students are spoon-fed and PowerPoint gives an impression of permanence, does not promote critical thought

- recent technical problems with $\mathrm{Bb}, \mathrm{html}$ editor not very good

nothing - 4

- nothing (2 responses)

- don't want to expand it's use any further, already at limit

- happy with content at present

large powerpoint files - 2

- problems with large PowerPoint files

- not user friendly, problems with large PowerPoint files 


\section{Questionnaire 2 ('Blackboard non-users')}

\section{Why do you not use Blackboard?}

easy to email students/ good for managing large student cohorts - 4

- as a filestore and for the email distribution list

- saves time and effort, popular with students, man management for large numbers students

- used as a central file store, easy to contact students by email as a single group

- much easier to upload information to $\mathrm{Bb}$ than to the web, email by groups is excellent, announcements is useful for first years

lack of time - 4

- lack of time and knowledge

- lack of time for voluntary activities

- lack of time, but now getting students asking for it

- lack of time

other - 9

- copyright, no time to update in three places - Bb, PowerPoint slides, www server

- don't know how to use it, only become convenor this year so not responsible before

- have not used $\mathrm{Bb}$, but co-opted on site for which is convenor

- have others put my lecture notes on Bb

- horror stories of losing the grades in the grade book, inertia to learn something new, time commitment

- inertia because info on web elsewhere

- just started at University and begun as course convenor

- not got into it yet

- departmental decision to stay with other web version of teaching material

\section{What prevents you from using $B b$ ?}

lack of time - 8

- lack of time (3 responses)

- lack of time and knowledge (2 responses)

- lack of time and training

- not had an opportunity to use it yet (2 responses)

lack of knowledge - 3

- lack of knowledge (3 responses)

other - 3

- copyright - not sure of provenance of images used

- do not like to have information that is changeable with author's name on it

- step change required, policy decision to go ahead now in place 